\title{
Fertilization Strategies In Pecan And Effects On Soil Properties And Plant Growth.
}

\author{
L. Giuffré ${ }^{1}$, E. Ciarlo ${ }^{1}$ E.B.Giardina ${ }^{1}$, C. Bonafina ${ }^{1}$ \\ ${ }^{I}$ Universidad de Buenos Aires. Facultad de Agronomía. .Buenos Aires, Argentina
}

\begin{abstract}
The pecan (Carya illinoensis Koch) is a fruit species belonging to the group of walnuts, a member of the family Juglandaceae, the same of the common walnut (Juglans regia) that besides being part of the culinary culture of Middle Eastern and European countries, has highly nutritious properties. The objectives of this work were to compare organic amendment vermicompost, with inorganic solid fertilizer in two doses (Fland F2) and a control without fertilization, and their effects on soil properties and plant development (height and diameter) from December 2012 to February 2015. Soil pH and EC values were unaffected neither by year $x$ treatment interaction effect nor by a treatment effect, even when $\mathrm{pH}$ values showed a very low variability among soil samples. EC showed a much higher variability between samples, especially at the latest season. Respect to plant growth the highest diameter was detected when an organic amendment or a high rate of a synthetic fertilizer were applied.The application of an organic amendment caused the highest levels of $C$ and $P$ in soils.
\end{abstract}

Keywords: Carya illinoinensis, fertilization effects, pecan growth, soil.

\section{Introduction}

The Native Americans used the pecan (Carya illinoensis Koch) as a food source for thousands of years before the arrival of European explorers. Native Americans and fur traders disseminated the nuts from the Mississippi Valley eastward. Pecans soon became an important trade item; the first shipment recorded to England was documented at 1761 [1]. The pecan is a fruit species belonging to the group of walnuts, a member of the family Juglandaceae, the same of the common walnut (Juglans regia). It is the only walnut of American origin, native of the South of the United States, extending through Texas and North of Mexico [2].

The main producing countries are the United States (72\%) and Mexico $(25 \%)$. Other smaller producers are Australia, South Africa, Israel, Brazil, Argentina, Peru and Egypt [3].

Good production will begin the ninth or tenth year, and trees can be productive for 100 years or longer. Pecans, like other fruit and nut trees, exhibit a characteristic called alternate bearing: trees produce an abundant crop one year and the following year relatively few fruits/nuts.

Soil samples should be taken for nutrient availability before planting. This will give an indication of the amendments required to make the soil as suitable as possible for pecan growth [4].

Economic advantage of pecan production is the extended harvest period as it is a perennial crop, and harvesting operations can be mechanized (not in small orchards). A major disadvantage of pecan culture is the length of time before pecans come into significant production (5 to 10 years). Similarly, the length of time necessary to fully renovate a neglected orchard may also be an impediment [1]. In North Carolina [5], for many generations, pecans have been grown on family homesteads in as part of a means for survival. Growing pecans requires patience and a long-term commitment. Some commercial pecan plantings in North Carolina are well over 75 years old and still very productive. Holdings of 20 to 30 trees are common. Whether you own a few trees or a commercial orchard, growing pecans can be enjoyable as well as profitable.

As it was cited in a previous work [6] it is relevant to consider [7] that besides being part of the culinary culture of Middle Eastern and European countries, has highly nutritious properties. The doctors recommend it for children with nutritional problems due to its constituents (protein, phosphorus, calcium, iron, potassium and vitamins A, B1, B2, B3, C, E and monounsaturated fatty acids). It reduces bad cholesterol, helps keep blood pressure low and is recommended especially for patients with cancer and cardiac problems.

Pecan tree is considered a "survivor". Along the 10.000 miles of rivers and streams in Texas there are many very large pecan trees which are living testimony of their tremendous survival potential. These trees have made it through extreme droughts such as the early 1950s where little or no rain occurred for four straight years, yet the pecan survived when other species of large trees died. The pecan is uniquely adapted to the hot, dry, windy Texas climate because it can tolerate stress. If pecans are stressed in the fall, they will not set a large crop the following year, and the tree will survive on food stored in the trees' massive limb, trunk and root system [8]. The Alabama Extension Service details several reasons by why pecan trees do not produce properly [9]: poor genetic value - variety (low production capacity, nut quality and susceptibility to disease); poor soil (growth and production is often poor on heavy clays, poorly drained soils and on deep sands unless an intensive irrigation and fertilization program is maintained); lack of lime in acid soils, nitrogen and zinc availabilities (common 
limiting factors); water (waterlogged soils do not provide aeration enough for roots, and lack of water, during dry periods during summer season, frequently results in reduced yields and quality); poor pollination (a single isolated pecan tree usually won't be effectively pollinated, most varieties shed pollen either too early or too late to pollinate the female flowers of the same tree, and rain may wash off pollen); overcrowding (pecan trees must have good exposure to sunlight to produce good crops); disease and insect pests. Pecan Cultivar Recommendations for the Southeast orchards in USA grouped by scab resistance were presented at the United States [10]. Another problem could be foxes, birds, peccaries and squirrels. Squirrels are often serious pests, especially if trees are located near a wooded area. No chemicals are currently legal in Argentina for killing squirrels or birds. However, barriers and trapping do offer some protection from squirrels [11].

Improved cultivars are extensively grown in the United States and abroad for commercial nut production, and also the demand for pecan wood has steadily increased in recent decades. It is used for furniture, cabinetry, pallets, and veneer. The wood has good machining properties, resembling those of true hickories [12]. Pecans grow well in a wide range of soil types including the red clays of extreme north Florida and the sandy soils of south central Florida. Best growth occurs in a sandy loam or loamy sand with a clay subsoil. The soil should be at least $1.5 \mathrm{~m}$ deep for optimum root penetration since the roots of mature pecan trees in a deep, welldrained soil may be more than 10 feet deep. Most of the feeder roots will be located in the upper $20 \mathrm{~cm}$ of soil [1].

The tree is adapted to the diverse environmental conditions but needs special care to produce high quality, well filled nuts, for example availability of water; a mature pecan tree requires nearly 34.000 gallons of water per year [13].

The first studies of the pecan as an alternative production in Argentina were conducted by INTA Delta technicians [14]. This crop can be found from Misiones to the lower Rio Negro valley, estimating the existence of about 5000 ha [15].

In a test carried out since the implantation of pecan at General Paz department (Buenos Aires province, Argentina) in 2008, it was observed after the first year, that phosphorus fertilization and the application of an organic amendment (compost) produced statistically significant increases of the soil extractable phosphorus, deficient in the studied soil [16].

During 2009-2010, organic amendments compost and vermicompost were compared with liquid fertilizer and a control without fertilization, and their effects were studied on soil and plant development [6]. The addition of vermicompost produced a significant increase $(5 \%)$ of soil $\mathrm{pH}$ compared to other treatments, but its value was close to neutral. It also produced a significant increase in electrical conductivity (EC), but within a normal range. Organic amendments also enhanced MBC (microbial biomass carbon), with statistically significant differences for the vermicompost. Both amendments presented statistically significant increases in tree height and diameter [6].

This long-term experiment continued over the years and the objectives of this work were to compare organic amendment vermicompost, with inorganic solid fertilizer in two doses (F1and F2) and a control without fertilization, and their effects on soil properties and plant development (height and diameter) from December 2012 to February 2015.

\section{Materials And Methods}

The experiment was developed in Villanueva, General Paz department, Buenos Aires Province (S Latitude $35^{\circ} 45^{\prime}$ and Longitude W $58^{\circ} 26^{\prime}$ ), on a soil classified as Thapto-argic Hapludoll [17]. The test was performed on a staggered distribution with $8 \mathrm{~m}$ x $8 \mathrm{~m}$ planting distance, with a randomized block design with four treatments and four replications (Table 1). Treatments were: synthetic fertilizers at a rate of $30 \mathrm{~g}$ per tree $(\mathrm{F} 1)$, and $60 \mathrm{~g}$ per tree $(\mathrm{F} 2)$, vermicompost at a rate $5 \mathrm{~kg} /$ tree $(\mathrm{V})$ and control without fertilization $(\mathrm{T})$. The synthetic fertilizers were urea $(\mathrm{CH} 4 \mathrm{~N} 2 \mathrm{O})$, potassium nitrate (KNO3) and Hydrocomplex (comercial blend with $\mathrm{N}: 12,4 \%$, P2O5 11,4\%, K2O 17,7\%, S 8\%, Fe 0,2\%,Mn 0,02\%, Zn 0,02\%, B 0,015\%). The vermicompost presented $23.55 \%$ C, 295 mg kg-1 extractable P, 491 mg kg-1 NO3, 689 mg kg-1 K, pH H2O:7.86, EC: 3.56 dS m-1 and 56.87\% ash. Fertilizers were applied at October 2011.

Drip irrigation was carried out during the months of highest evapotranspiration (November to March) delivering 4 liters m-2 day-1. The water came from a mill that is on the farm. Periodic cuts of lawn were made to avoid interspecific competition.

Soil sampling was performed in the planting hole of each pecan plant for the different treatments and replications considered in the test, one year after the fertilizers were applied. It was performed with a manual soil auger up to a depth of $20 \mathrm{~cm}$. Three simple samples were taken per hole, which were then composed into a single composite sample per plant. The same day soil samples were taken, measurements of trees height and stem diameter were carried out, considering a tree per replication. Sampling dates for soil and plants were: December 2011, December 2012, February 2013 and February 2014. Soil samples were subject of the following 
Fertilization strategies in pecan and effects on soil properties and plant growth.

analysis: $\mathrm{pH}$ (1:2.5 soil water), electrical conductivity EC, oxidizable carbon and extractable phosphorous (Bray \& Kurtz 1 extractant).

Table 1: Diagram of the experiment, staggered distribution, $8 \times 8 \mathrm{~m}$.

\begin{tabular}{|l|l|l|l|l|l|l|l|}
\hline & T1 & & F11 & & F21 & & V1 \\
\hline & & & & & & & \\
\hline F22 & & T2 & & V2 & & F12 & \\
\hline & & & & & & & \\
\hline & V3 & & F23 & & F13 & & T3 \\
\hline & & & & & & & \\
\hline F14 & & V4 & & T4 & & F24 & \\
\hline
\end{tabular}

A. Statistical analysis

Data were processed using the Infostat Statistics Package (2007). The analyzed parameters were firstly checked for normality and then subjected to analysis of variance (ANOVA).

A. Soil properties

\section{Results And Discussion}

Soil $\mathrm{pH}$ and EC values were unaffected neither by year $\mathrm{x}$ treatment interaction effect nor by a treatment effect (Figs. $1 \mathrm{a}$ and b), even when $\mathrm{pH}$ values showed a very low variability among soil samples $(\mathrm{CV}=6.15 \%)$. EC showed a much higher variability between samples, especially at the latest season. Salinity, expressed in terms of EC, seemed to be initially increased by organic amendment application, which is usual when using this kind of fertilization. However, this effect disappeared over time.

a)
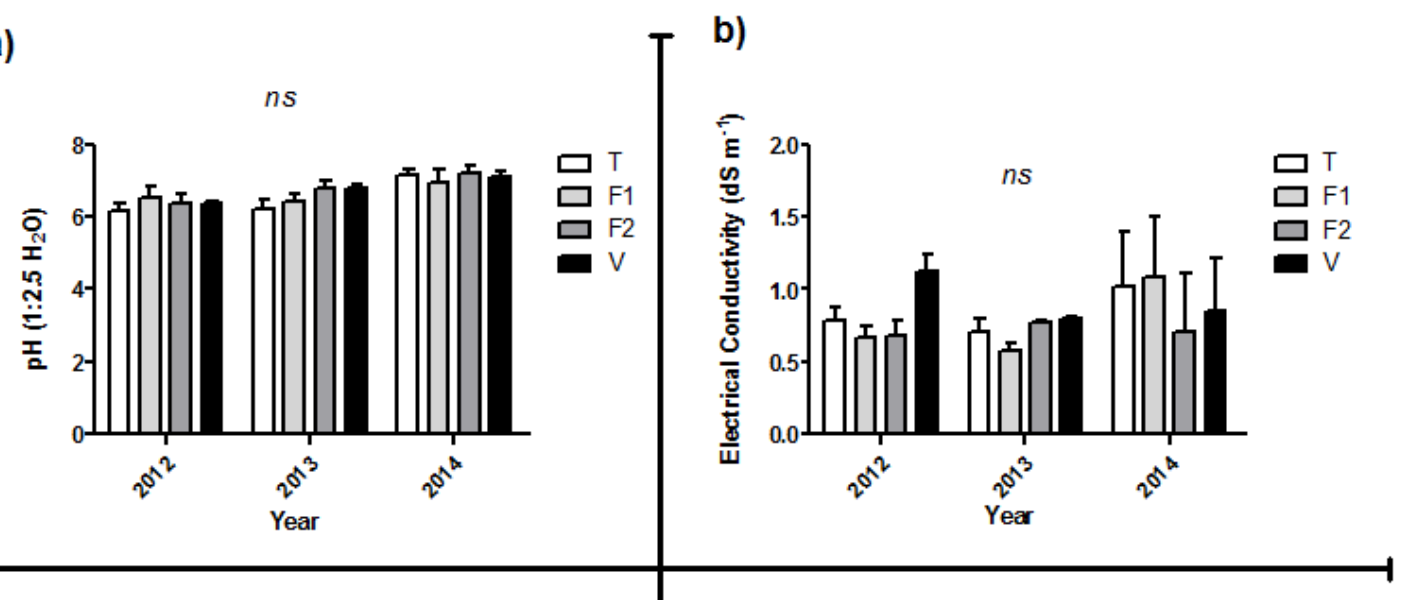

c)
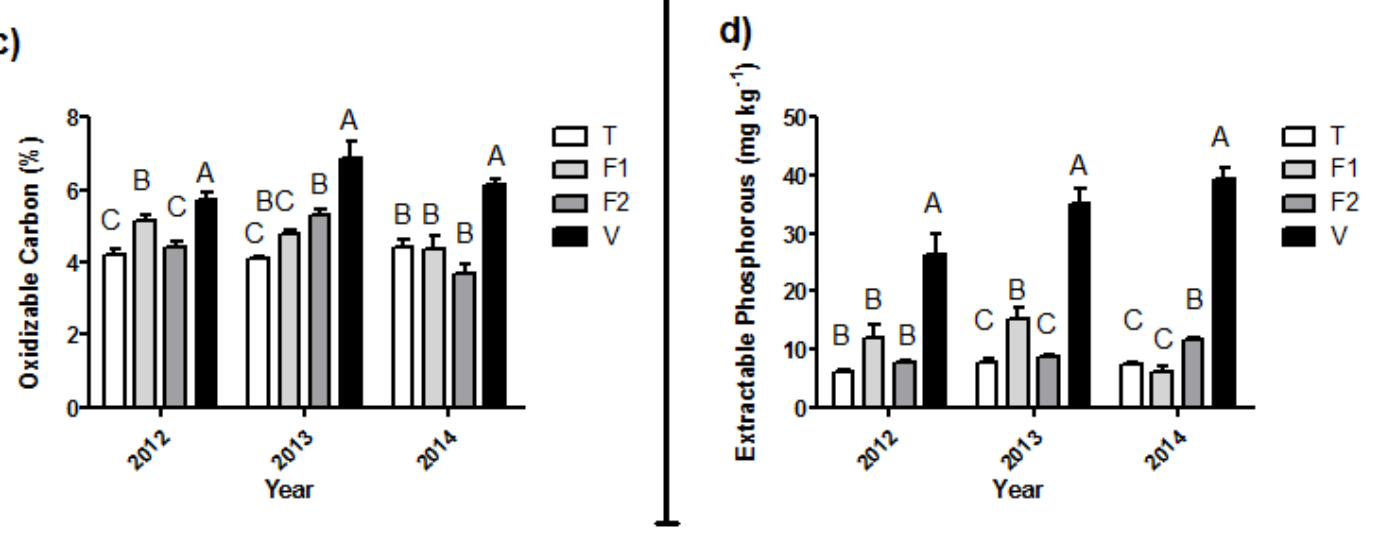

Figure 1. Soil pH in a 1:2,5 soil:water relationship (a), electrical conductivity EC (b), oxidizable carbon content (c) and phosphorous availability (B\&K 1). T represents the unfertilized situation, F1 and F2 represent growing rates of a mixture of synthetic fertilizers, and V represent the organic amendment. Different letters indicate significant differences between treatments $(p<0.05)$ and ns indicate the absence of such differences in each season. 
On the contrary, oxidizable carbon, representing total organic carbon, and extractable $\mathrm{P}$ were affected by a strong $(p<0.001)$ year $x$ treatment interaction effect (Figs. $1 \mathrm{c}$ and $\mathrm{d})$. For both elements, the organic amendment clearly surpassed their contents at the other fertilization treatments. These results were sound since the organic amendment offered the highest amount of $\mathrm{C}$ and $\mathrm{N}$; however, the carry-over effect after several years since the application was marked.

\section{B. Plant growth}

Plant growth was evaluated and expressed as the difference in diameter (or height between two consecutive years). Trees diameter presented a significant $(\mathrm{p}=0.01)$ year $\mathrm{x}$ treatment interaction effect. Stem diameter was unaffected by fertilization treatments in the first year after fertilization, but in the latest seasons (2013 and 2014), statistical differences between treatments were detected (Fig. 2).

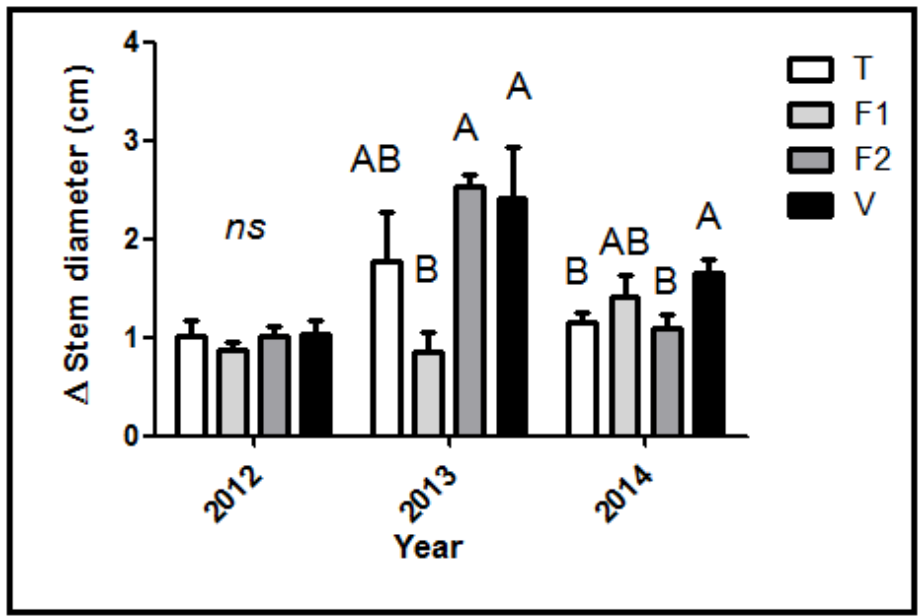

Figure 2. Stem diameter annual variation $(\mathrm{cm})$ at the chest height at different seasons and treatments. T represents the unfertilized situation, F1 and F2 represent growing rates of a mixture of synthetic fertilizers, and $\mathrm{V}$ represent the organic amendment. Different letters indicate significant differences between treatments $(\mathrm{p}<$ 0.05 ) and ns indicate the absence of such differences in each season.

At the second year of sampling, the highest growth in diameter was detected when an organic amendment or a high rate of a synthetic fertilizer were applied. At the latest season (2014) the organic amendment supported the highest rate in diameter increase.

Trees height presented a significant $(\mathrm{p}=0.02)$ year $\mathrm{x}$ treatment interaction effect. Stem diameter was unaffected by fertilization treatments in the first and in the third year after fertilization, but in the second season (2013), statistical differences $(p=0.09)$ between treatments were detected (Fig. 3). Surprisingly, the treatment with the highest increase in height at 2013 was the unfertilized situation.

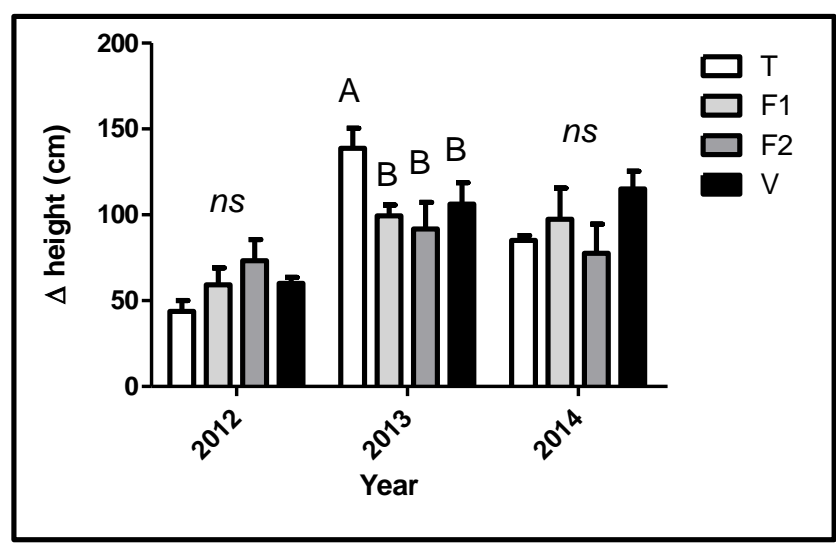

Figure 3. Height annual variation $(\mathrm{cm})$ at the chest height, at different seasons and treatments. $\mathrm{T}$ represents the unfertilized situation, F1 and F2 represent growing rates of a mixture of synthetic fertilizers, and $\mathrm{V}$ represent the organic amendment. Different letters indicate significant differences between treatments $(\mathrm{p}<$ 0.1 ) and ns indicate the absence of such differences in each season. 
Even when pecan trees are usually planted with the aim to generate an economic income, there are other advantages related to such productions. The following benefits of trees to the community can be highlighted: supply oxygen, sequester carbon dioxide, reduce noise pollution, trap particulate materials, alter microclimate, improve aesthetics, enhance outdoor urban spaces, and benefit the community's character [18]. The intrinsic beauty of pecan trees in the landscape of a home or community is difficult to quantify. However, a reasonable estimate is that trees increase the value of a home by about $1 \%$ per year; thus, a $\$ 100,000$ home that is 25 years old would have an additional worth of about $\$ 25,000$ because of the mature landscaping [19]. While the value of the pecan industry can easily be measured from a nut production standpoint, there are other, less obvious, benefits to the community benefits difficult to quantify, and it's even more difficult to define their dollar value. Hence, the values are noncommensurable, since they do not have a common unit of measure [19].

\section{Conclusion}

As can be concluded from the results, the application of an organic amendment caused the highest levels of $\mathrm{C}$ and $\mathrm{P}$ in soils. The higher contents of these elements are reflected in a larger diameter growth, but these soil conditions did not seem to affect growth in height; it is likely that the latter growth is more related to environmental factors such as intraspecific competition. Salinity, expressed in terms of EC, seemed to be initially increased by organic amendment application, which is usual when using this kind of fertilization. However, this effect disappeared over time; on the contrary, synthetic fertilizers did not increase EC in this soil. Although it is not related with our results, it may be remarkable that pecan trees are usually grown for commercial production, but also can improve enjoyment, by means of the benefits for community and landscape, and also for medicinal effects.

\section{Acknowledgements}

This work was founded by Project UBACyT 20020130100164BA 2014-2017.

\section{References}

[1]. P.C. Andersen. The Pecan Three (IFAS Extension University of Florida, 2004) http://edis.ifas.ufl.edu/pdffiles/HS/HS22900.pdf. Last Acces: 02/22/2017.

[2]. G Lemus. El cultivo del pecano. (Gobierno de Chile. Ministerio de Agricultura. INIA La Platina. Fundación para la innovación Agraria FIA). 2004.

[3]. Fundación Produce. A.C. e INIFAP Sonora. Cadena Agroalimentaria (Agroindustrial Nogal Pecanero 2002).

[4]. L Wells. Establishing a Pecan Orchard. University of Georgia. (UGA Cooperative Extension Bulletin 1314 2012). www.Georgia\%20Pecan\%20orchard\%202012.PDF

[5]. N.C North Carolina State University. Cooperative Extension. Growing Pecans in North Carolina. 2015 https://content.ces.ncsu.edu/growing-pecans-in-north-carolina

[6]. L Giuffré, R. Romaniuk, R. P. Ríos and M. M. Zubillaga. 2011. Sustainable management in pecan cultivation in Argentina. Emirates Journal of Food and Agriculture 23 (3): 243-248

[7]. $\mathrm{R}$ Marín and G. Borestti. Revista Digital de Innovación Tecnológica. Número $4.2008 . \quad$ http://www.cinntec .misiones.gov.ar/index.php.

[8]. G.R. Mc Eachern. Evaluating Pecan Problems. Fact Sheets (Texas A\&M University 1995). http://aggie-horticulture.tamu.edu/fruitnut/fact-sheets/evaluating-pecan-problems/ Last Acces: 02/22/2017

[9]. B Goff B. 2011. Seven reasons pecan trees don't produce. (Alabama Cooperative Extension System) www.aces.edu/ dept/extcomm/specialty/pecans $2 . h t m l$

[10]. B Goff B.2015 Pecan Cultivar Recommendations for the Southeast - 2014-15 Update http://www.alabamapecangrowers. com/cultivars.html

[11]. B Polomski. and D. Shaughnessy. Pecan Planting \& Fertilization (Clemson University 2015). www.clemson. edu/extension/ hgic/plants/vegetables/tree_fruits_nuts/hgic1356.html

[12]. J.K.Peterson. Pecan. (US Forest Service 1990). http://www.na.fs.fed.us/Spfo/pubs/silvics_manual/volume_2/carya/illinoesis.htm

[13]. R.E. Call, R. Gibson and M.W. Kilby. Pecan Production Guidelines For Small Orchards And Home Yards. (University of Arizona 2006). https://extension.arizona.edu/sites/extension.arizona.edu/files/pubs/az1400.pdf Last Acces: 02/22/2017.

[14]. E Madero. Nuez pecán. Interesante alternativa para el NOA. Comunicaciones INTA: 51. 2009.

[15]. E Madero, and E Frusso. La nuez pecán en Argentina. Curso sobre Pecán. INIA Instituto Nacional de Investigación Agropecuaria. Las Brujas. Uruguay 2009

[16]. L Giuffré, M. M. Zubillaga, R. I, Romaniuk, R.P. Ríos \& M. Hilding Ohlson. 2011. Fertilización de base en un cultivo inicial de pecan con dos marcos de plantación de alta densidad. Ciencia del suelo 29(1): 91-97.

[17]. Soil Survey Staff. Keys to Soil Taxonomy (12th ed. USDA-Natural Resources Conservation Service, Washington, DC 2014)

[18]. J.R. Hartman, T.P. Pirone and M.A. Sall. 2000. Pirone's Tree Maintenance. (7th ed. Oxford Univ. Press, N.Y 2000)

[19]. J.G. Mexal, E.A. Herrera, T.W. Sammis and, W.H. Zacris. Non commensurable values of the pecan industry. Guide H-654 (NMSU. New Mexico State University 2008). http://aces.nmsu.edu/pubs/_h/H654.pdf 